\title{
MEMES, TECNOLOGIAS E EDUCAÇÃO: ‘CONVERSAS’ COM PROFESSORAS EM TEMPOS DE PANDEMIA
}

\author{
MEMES, TECHNOLOGIES AND EDUCATION: 'CONVERSATIONS' WITH TEACHERS IN TIMES \\ OF PANDEMIC
}

\section{MEMOS, TECNOLOGÍAS Y EDUCACIÓN: 'CONVERSACIONES' CON LOS MAESTROS EN TIEMPOS DE PANDEMIA}

\section{Elaine Sotero ${ }^{1}$}

Brenda Coutinho

\begin{abstract}
RESUMO
O foco do artigo é evidenciar a importância das tecnologias digitais durante a pandemia do COVID-19, pois o uso desses artefatos tecnológicos vem sendo cada vez mais imprescindível na atual conjuntura. O referente trabalho tem como objetivo mostrar como as tecnologias digitais estão sendo utilizadas para proporcionar diferentes interações no contexto educativo, como aulas remotas, criação de materiais didáticos, memes educativos, debates nas redes socias, lives e etc... Nesse momento, em que os encontros presenciais estão restringidos, e que as escolas estão fechadas, a importância da educação é cada vez mais evidenciada, pois a mesma vem sendo negligenciada há anos por governos e por outros setores da nossa sociedade. Estamos vivenciando um momento político e social que nos permite dar uma resposta contrária à banalização que vem vivendo a educação. Ou seja, este momento contraria a posição de que a escola pode ser descartável e substituível por classes em casa, por exemplo: 'homeschooling'. Ao contrário disso, a educação escolar se faz necessária em todos os contextos históricos da sociedade, sejam elas quais forem. Assim, tentamos compreender como questões socias de gravidade, como a pandemia em curso, podem se transformar em questões curriculares, mediadas pelas tecnologias e por suas criações? Como será o mundo e as escolas póspandemia? Estes são questionamentos que estamos gestando agora e que esse artigo busca refletir sobre.
\end{abstract}

PALAVRAS-CHAVE: Pandemia. Redes educativas. Memes.

\section{ABSTRACT}

Submetido em: 29/04/2020 - Aceito em: 07/08/2020 - Publicado em: 18/08/2020.

${ }^{1}$ Pedagoga, mestranda em Educação no Programa de Pós Graduação em Educação (ProPEd-UERJ) com bolsa do Cnpq - membro do GRPesq 'Currículo, redes educativas, imagem e sons' coordenado pela professora Nilda Alves - pesquisa sobre as relações entre a trajetória de mulheres negras migrantes, representadas nos filmes e as experiências de mulheres negras brasileiras, pensando a importância dessa questão nas redes educativas, nos cotidianos e nos currículos.

${ }^{2}$ Graduada em Pedagogia pela Universidade do Estado do Rio de Janeiro - UERJ (2018), com Licenciatura plena em Pedagogia para a Educação Básica. Membro do GRPesq 'Currículo, redes educativas, imagem e sons' coordenado pela professora Nilda Alves. 
The focus of the article is to highlight the importance of digital technologies during the COVID-19 pandemic, as the use of these technological devices is becoming increasingly essential in the current situation. The purpose of this work is to show how digital technologies are being used to provide different interactions in the educational context, such as remote classes, creation of teaching materials, educational memes, debates in social networks, lives and etc ... At that moment, when face-to-face meetings are restricted and schools are closed, the importance of education is increasingly evident, as it has been neglected for years by governments and other sectors of our society. We are experiencing a political and social moment that allows us to respond against the trivialization of education. In other words, this moment contradicts the position that the school can be disposable and replaceable with classes at home, for example: 'homeschooling'. On the contrary, school education is necessary in all historical contexts of society, whatever they may be. So, we try to understand how social issues of gravity, like the current pandemic, can turn into curricular issues, mediated by technologies and their creations? What will the world and post-pandemic schools be like? These are questions that we are raising now and that this article seeks to reflect on.

KEYWORDS: Pandemic. Educational. networks. Memes.

\section{RESUMEN}

El objetivo del artículo es resaltar la importancia de las tecnologías digitales durante la pandemia de COVID19, ya que el uso de estos dispositivos tecnológicos es cada vez más esencial en la situación actual. El propósito de este trabajo es mostrar cómo se utilizan las tecnologías digitales para proporcionar diferentes interacciones en el contexto educativo, como clases remotas, creación de materiales didácticos, memes educativos, debates en redes sociales, vidas, etc. En ese momento, cuando Las reuniones cara a cara están restringidas y las escuelas están cerradas, la importancia de la educación es cada vez más evidente, ya que ha sido descuidada durante años por los gobiernos y otros sectores de nuestra sociedad. Estamos viviendo un momento político y social que nos permite responder contra la trivialización de la educación. En otras palabras, este momento contradice la posición de que la escuela puede ser desechable y reemplazable con clases en el hogar, por ejemplo: "educación en el hogar". Por el contrario, la educación escolar es necesaria en todos los contextos históricos de la sociedad, sean cuales sean. Entonces, ¿tratamos de entender cómo los problemas sociales de la gravedad, como la pandemia actual, pueden convertirse en problemas curriculares, mediados por las tecnologías y sus creaciones? ¿Cómo serán el mundo y las escuelas pospandémicas? Estas son preguntas que estamos planteando ahora y sobre las cuales este artículo busca reflexionar.

PALABRAS CLAVE: Pandemia. Redes educativas. Memes.

\section{INTRODUÇÃO}

Há muito, membros e membras do grupo de pesquisa em que atuamos nos possibilitam diversas reflexões nas 'conversas' que tecemos acerca da atual conjuntura em que vivemos. Temos visto o mundo inteiro padecer com a disseminação de um novo vírus chamado de Covid-19. As mídias sociais vêm contribuindo como uma importante ferramenta de fontes de informações e criações pelo mundo, embora também disseminem notícias falsas, as chamadas fakenews. Percebemos que esse movimento com imagens e narrativas nos faz pensar acerca da educação de uma maneira mais ampla. Partindo da ideia de criação de 
'conhecimentossignificações'3 em múltiplas redes educativas - que nos formam e que por nós são formadas - o presente artigo tem como interesse conversar com e fazer 'uso' (CERTEAU, 1994) de algumas imagens e narrativas de memes criados e articulados em torno do novo coronavírus para pensarmos na educação, nos currículos e nos cotidianos escolares.

A internet produziu várias novidades que mudaram as nossas práticas e a nossa condição de nos conectar com o mundo. Fazemos uso, da internet em vários artefatos culturais como: tablets, celulares (smartphones), laptops, computadores, TVs, entre outros. A todo o momento, em diversas redes sociais, com uma multiplicidade de ofertas e singularidades de uso, interagimos via WEB (Rede Mundial de Computadores/Internet). Essa diversidade de artefatos tecnológicos se insere no universo da chamada Cibecultura que Pierry Levy, elucida bem em sua definição.

O termo [ciberespaço] especifica não apenas a infraestrutura material da comunicação digital, mas também o universo oceânico de informação que ela abriga, assim como os seres humanos que navegam e alimentam esse universo. Quanto ao neologismo 'cibercultura', especifica aqui o conjunto de técnicas (materiais e intelectuais), de práticas, de atitudes, de modos de pensamento e de valores que se desenvolvem juntamente com o crescimento do ciberespaço (LÉVY, 1999, p. 17).

A cibercultura também é uma maneira nova de nos manter conectados, atualizados, propiciando novas possibilidades de nos relacionarmos com o mundo de forma virtual, por meio da internet.

Segundo Paiva (2005), vivemos hoje num momento de grande ebulição tecnológica. Os artefatos culturais tecnológicos são símbolos dominantes desse período histórico que vivenciamos se pensarmos na quantidade deles, como: smartphone, notebooks, tablets, redes sociais, comércio eletrônico, banco digital, serviços voltados para as mobilidades urbanas amparados em geolocalização e conexão em rede como 99, Uber, BlaBlaCar, entre outras práticas mediadas em rede que representam nosso comportamento atual, veremos que é através deles, por sua portabilidade e interação que vêm se modificando 'espaçostempos' nos processos produtivos. Essas interações se dão em tempo real com espaços múltiplos, algo antes inimaginável.

\footnotetext{
${ }^{3}$ Lembramos que a junção das palavras é uma aposta política dos estudos com os cotidianos, inspirada em Alves (2010), na tentativa de produzir sentidos diferentes e maiores para as palavras agrupadas, mas sem tirar o sentido original de cada uma, superando a dicotomia "estabelecida" pela ciência moderna e abrindo novas possibilidades de reflexão a partir desta estética de escrita.
} 


\section{ALGUMAS CONSIDERAÇÕES ACERCA DO COVID-19}

Como sabemos, o mundo inteiro está sofrendo com a disseminação de um novo vírus chamado Covid_19. Mas que vírus é esse? Do ponto de vista da Biologia, vírus são organismos microscópicos que não possuem células. Não conseguem viver sozinhos e necessitam de outras vidas (hospedeiros) para se multiplicar (WESSNER, 2010).

No final do ano de 2019, começaram a surgir, repentinamente, vários casos de uma suposta pneumonia em Wuhan, capital da província de Hubei, na China. De fato, esse acontecimento indicava que alguma coisa nova estava infectando pessoas. As autoridades acreditavam que uma das hipóteses seria de que o surto se originou em um dos mercados de Wuhan. Nesses mercados chamados "mercados molhados", animais são vendidos vivos ou mortos na hora. Como seus restos ficavam espalhados pelo chão, esta poderia ser uma das causas da transmissão, já que uma pandemia anterior chamada de 'gripe aviária' (H1n1), era oriunda de aves. É provável que devido a isto, um vírus de um animal que ainda não se sabe a espécie tenha sido passado para o ser humano. Existem vírus e bactérias que se hospedam em animais sem causar dano algum ao bicho e esses micro-organismos podem sofrer mutações e acabar infectando o ser humano que tenha tido contato com esses animais. Só que no caso da COVID - 19 esta hipótese da transmissão animal não se confirmou e há possibilidade de que ela seja uma mutação de outros vírus não encontrado na China. Ou seja, há ainda muitas incertezas quanto à origem, a potencialidade e os tratamentos, destacando-se que não há ainda uma vacina.

Manter o isolamento social é uma situação antes inimaginável, todo o funcionamento de nossa sociedade é baseado no encontro físico das pessoas. Para os cotidianos escolares, o ato estar presente no espaço físico é essencial, pois lá, além das trocas de 'conhecimentossignificações', as escolas, principalmente as públicas, são as instituições que garantem direitos básicos de qualquer criança, como a alimentação. Crianças mais novas, ainda não têm maturidade para entender de fato o que vem acontecendo no Brasil e no mundo. A importância das possibilidades oferecidas na cibercultura, nesses tempos difíceis, vão além de nos manter informados e de ajudar a não nos contaminarmos com esse vírus tão ardiloso e contagioso. Ela nos proporciona vivências de um 'estar junto virtual', por meio de interações em diferentes redes e plataformas.

\section{CONVERSAS ENTRE PEDAGOGAS ACERCA DOS USOS DE ARTEFATOS TECNOLÓGICOS EM TEMPOS DE PANDEMIA: 'SENTIRFAZERPENSAR' COM RELATOS E TROCAS}


Uma das autoras trabalha há quase um ano em uma creche da rede privada no Rio de Janeiro de ensino com crianças de classe média. A turma pertence ao segmento da Educação Infantil e a instituição a define como berçário 2. O ambiente de trabalho é composto por uma equipe na qual existe uma regência e auxiliares. Diante da ameaça evolvendo a saúde da população, a escola seguiu os decretos dos governantes e do Ministério da Saúde e realizou o encerramento das atividades educacionais no dia 17 de março, até que houvesse uma resposta dos setores da saúde para o retorno do funcionamento da instituição. Com isso, uma dúvida entre os professores se estabeleceu: de que maneira manteríamos o contato com as crianças? A atuação na educação infantil se dá principalmente através da ludicidade, com inúmeras brincadeiras, que envolviam músicas, contações de histórias e etc. Todas elas envolvem o contato direto entre educadores e crianças, é impossível pensar uma educação infantil além dessa maneira.

Porém, diante dessa pandemia e com a instituição fechada, foi sugerido pela creche que a equipe de cada turma se comunicasse com as crianças, através de filmagens feitas por celulares ou outro aparelho eletrônico que estivesse à disposição, e logo após encaminhando às famílias das crianças através das mídias sociais. As gravações têm como objetivo manter a comunicação da equipe educacional com a turma. Esta proposta gerou um enorme desafio entre os professores e os auxiliares. $\mathrm{O}$ uso de um artefato tecnológico trouxe consigo uma problemática carregada de outros questionamentos como por exemplo: de que forma docentes que não possuem familiaridade com as novas tecnologias midiáticas online podem reagir a esta demanda?

O desafio foi lançado, Brenda se considera desinibida no espaço físico de trabalho que é a sala de aula. Entretanto, perante as câmeras foi tomada por um receio de fraquejar, então em um ato de resistência e criação pensou em algumas ideias para o período. Após inúmeras 'conversas' ${ }^{4}$ e trocas colaborativas com amigas, chegou à conclusão que não deveria se permitir a uma resistência aos artefatos tecnológicos, pois os mesmos possuem sua devida relevância, e já estão inseridos nos 'espaçostempos' educacionais. Essas 'conversas' nos permitiram mudanças significativas, pois o roteiro do vídeo proposto pela escola e esse presente texto só pode ser escrito pela realização dessas tantas 'conversas'. Alves (2012) afirma que é por isto que reconhecemos qualquer texto possui sempre uma autoria coletiva.

Brenda compreendeu que não poderia ser julgada por não possuir uma maior familiaridade diante de um artefato de filmagem e que essa insegurança não poderia desanimá-la

\footnotetext{
${ }^{4}$ Nas pesquisas com os cotidianos as 'conversas' são entendidas como o principal lócus de trabalho e produção de 'conhecimentossignificações'.
} 
enquanto pedagoga. Para Santos (2014), os saberes da docência online são espaços vividos e construídos no devir da cibercultura. Brenda enfrentou essa missão e sua gravou um vídeo conversando com os bebês que já a conhecem desde o berçário1 e, logo após, cantou uma música que as crianças costumam cantarolar antes do almoço para a higienização das mãozinhas. Brenda ampliou e utilizou imagens ilustrativas da turma da Mônica que estão sendo vistas em várias mídias sociais. As crianças gostaram muito. Assim, vários pais mandam mensagem dizendo que as crianças pediam para assistir o vídeo a todo o momento. Dessa forma, artefatos culturais digitais se transformaram em artefatos curriculares, proporcionando uma aproximação dos educadores com seus educandos.

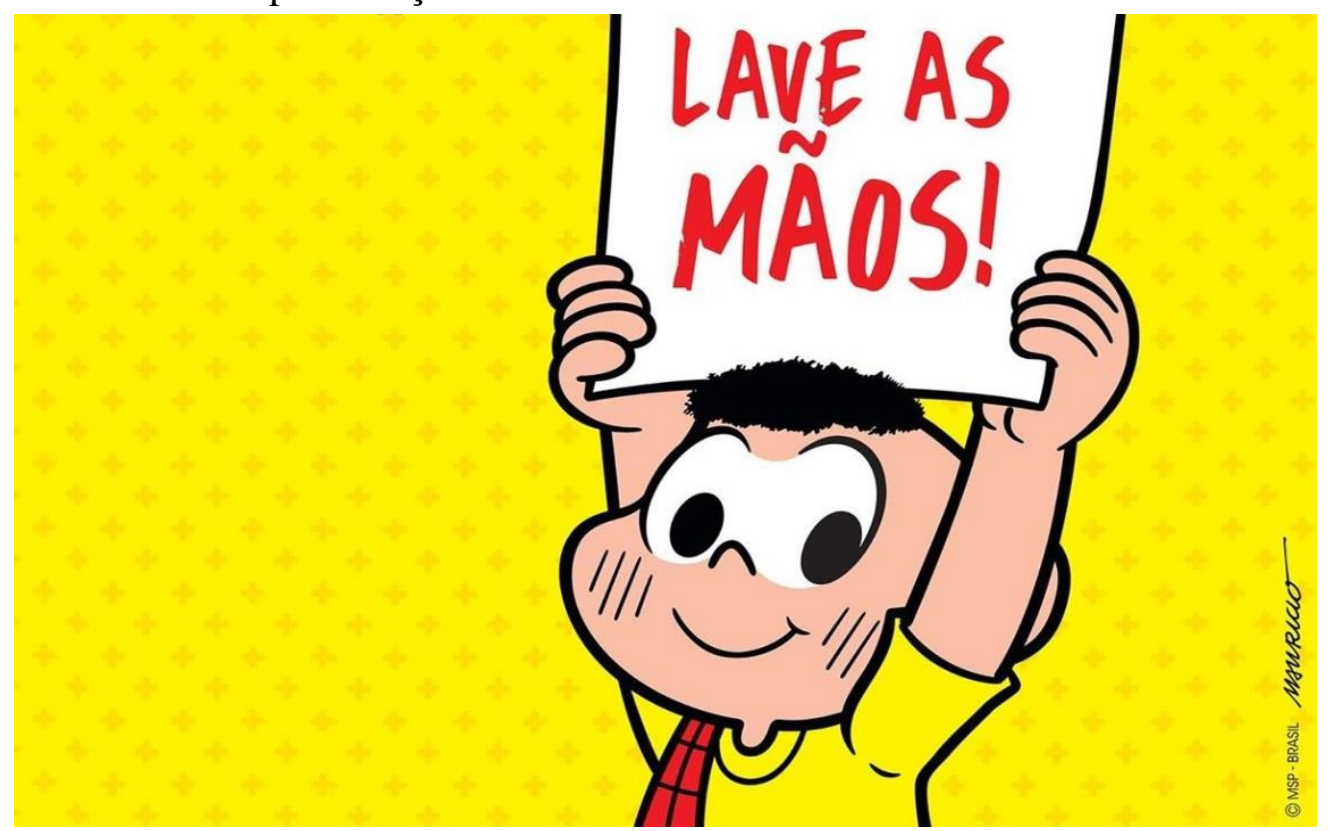

Figura 1. Plano de proteção contra o Coronavírus

Fonte: https://cutt.ly/ldQhNcr

\section{MEMES EM ATAQUE AO CORONAVÍRUS}

Mas afinal, o que são memes? De acordo com a Wikipédia, o termo "meme" surgiu em 1976, tendo como origem o conceito criado por Richard Dawkins, ao estudar os modelos evolutivos da transferência de informação (Wikipédia, 2016a). No contexto da internet, o termo é utilizado para descrever um conceito de GIFs, imagens, vídeos, geralmente relacionados ao humor, que se espalham entre internautas: Os memes presentes em nossos 
cotidianos são vistos como uma distração ou um entretenimento, mas podem ser utilizados também como ferramenta de ludicidade e aprendizagem em 'espaçostempos' escolares.

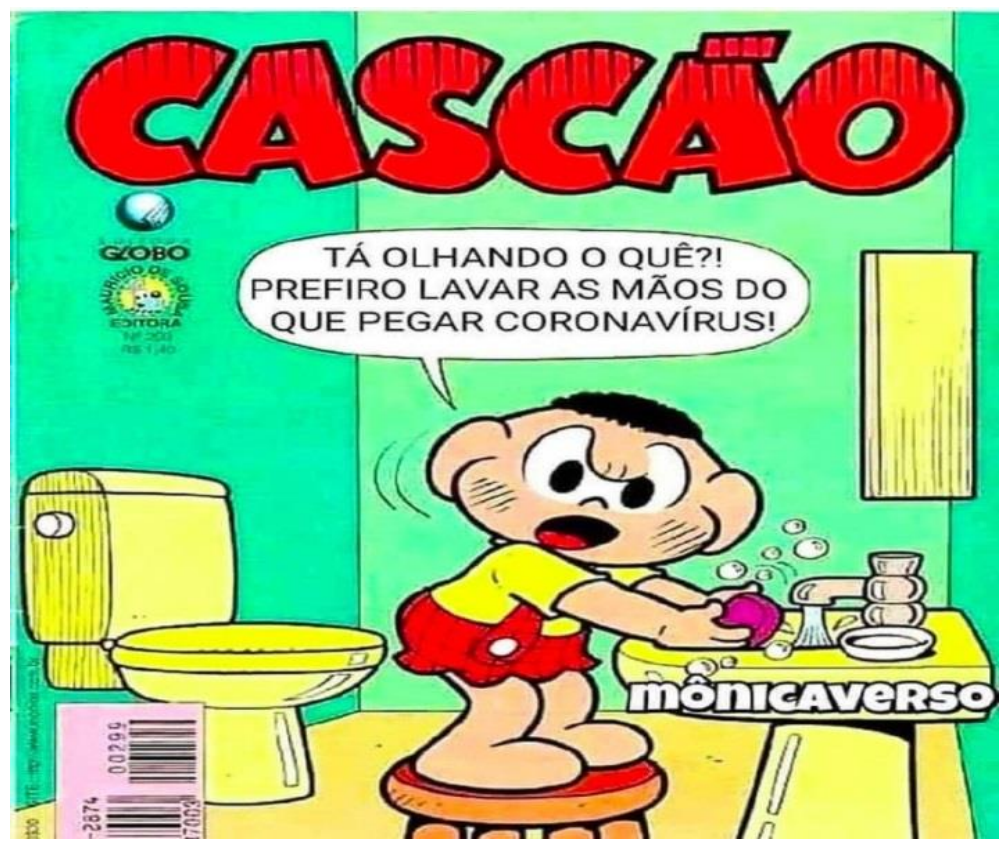

Figura 2. Cascão

FONTE: https://url.gratis/JohRO

Nas pesquisas 'nosdoscom' os cotidianos, acreditamos que nossas experiências imagéticas e sonoras são marcantes para a nossa formação pessoal e identitária (ALVES, 2011). Nesta mesma perspectiva, Nilda Alves (2011), nos traz há alguns anos a importância das imagens na tessitura de 'conhecimentossignificações' e enfatiza ainda que os currículos também são tecidos por elas. Estas imagens funcionam para nós como personagens conceituais DELEUZE, GUATTARI, 1992), agindo como intercessores de nossos pensamentos. Alves (2011), elucida sobre esse conceito:

Os personagens conceituais são, assim, aquelas figuras, argumentos ou artefatos que entram como o outro - aquele com que se 'conversa' e que permanece presente muito tempo para se acumular ideias necessárias ao desenvolvimento de conhecimentos e a compreensão de significações nas pesquisas que desenvolvemos. Esses personagens conceituais aí têm que estar, para que o 
pensamento se desenvolva, e para que novos conhecimentos apareçam, para que lógicas se estabeleçam. (ALVES, 2011, p.13).

Os personagens conceituais, como as imagens e narrativas, não devem ser somente entendidos, como 'fontes' ou como 'recursos metodológicos', para nós que pesquisamos os cotidianos nossa preocupação é buscar compreender como esses artefatos culturais passam a serem artefatos curriculares, uma vez que estão presentes na tessitura de 'conhecimentossignificações' nos múltiplos cotidianos escolares. Alves nos explica como funcionam estes processos curriculares:

\footnotetext{
entendo os currículos como articulação entre problemas sociais e as ações e experiências desenvolvidas nas escolas, buscando compreender a multidão de seres que nisto está envolvida, numa clara tentativa de pensar junto EDUCAÇÃO e ENSINO, este 'entrelugares' ocupado pelos currículos oficiais e aqueles criados nos cotidianos escolares, em conjuntos com as propostas a eles feitas pelos praticantespensantes das diversas redes educativas. $(2017$, p.3)
}

Desta forma, vemos que os currículos não são somente aquilo que 'dita' o que os professores devem ensinar em sala de aula, mas sim os processos de entrelaçamento entre as diversas redes dos 'praticantespensantes' que frequentam o 'dentrofora' das escolas. Os currículos não são tecidos somente nas diretrizes, nos parâmetros organizados no nível macro estrutural pelas forças governamentais, distantes do cotidiano escolar. Pelo contrário, os currículos: "têm sua presença nas escolas trançadas com inúmeras ações curriculares cotidianas, desenvolvidas por docentes e discentes e cujas origens estão em diversas redes educativas" (ALVES, 2017, p. 8). É nesta relação entre os agentes que ocorrem os processos curriculares e consequentemente a criação dos currículos nos cotidianos. Considerando estas questões fica evidente a importância das imagens e narrativas nos atos de 'verouvirsentirepensar' que estão presentes nos cotidianos escolares.

Esses novos artefatos culturais, os 'memes', podem parecer um singelo entretenimento que os internautas fazem uso (CERTEAU, 1994) seja para alertar, ironizar ou até mesmo apavorar a população que no momento vive essa difícil pandemia, mas carregam em suas significações potências curriculares de caráter educativo. 


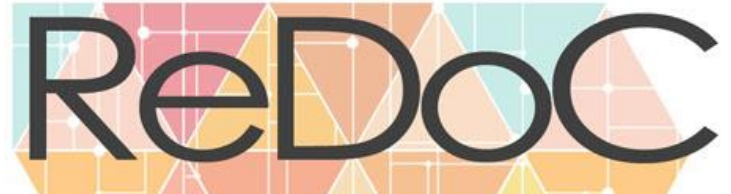

Revista Docência e Cibercultura

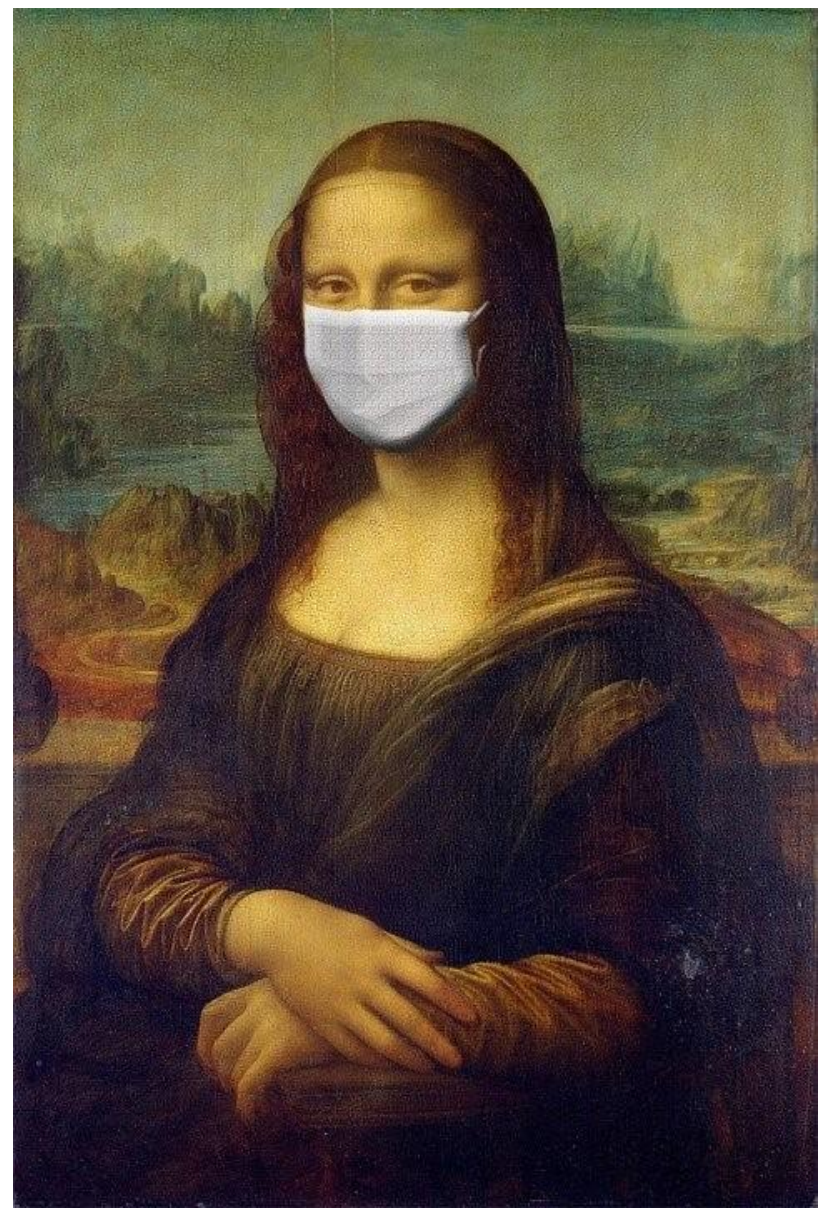

Figura 2. Foto pintura da Mona Lisa

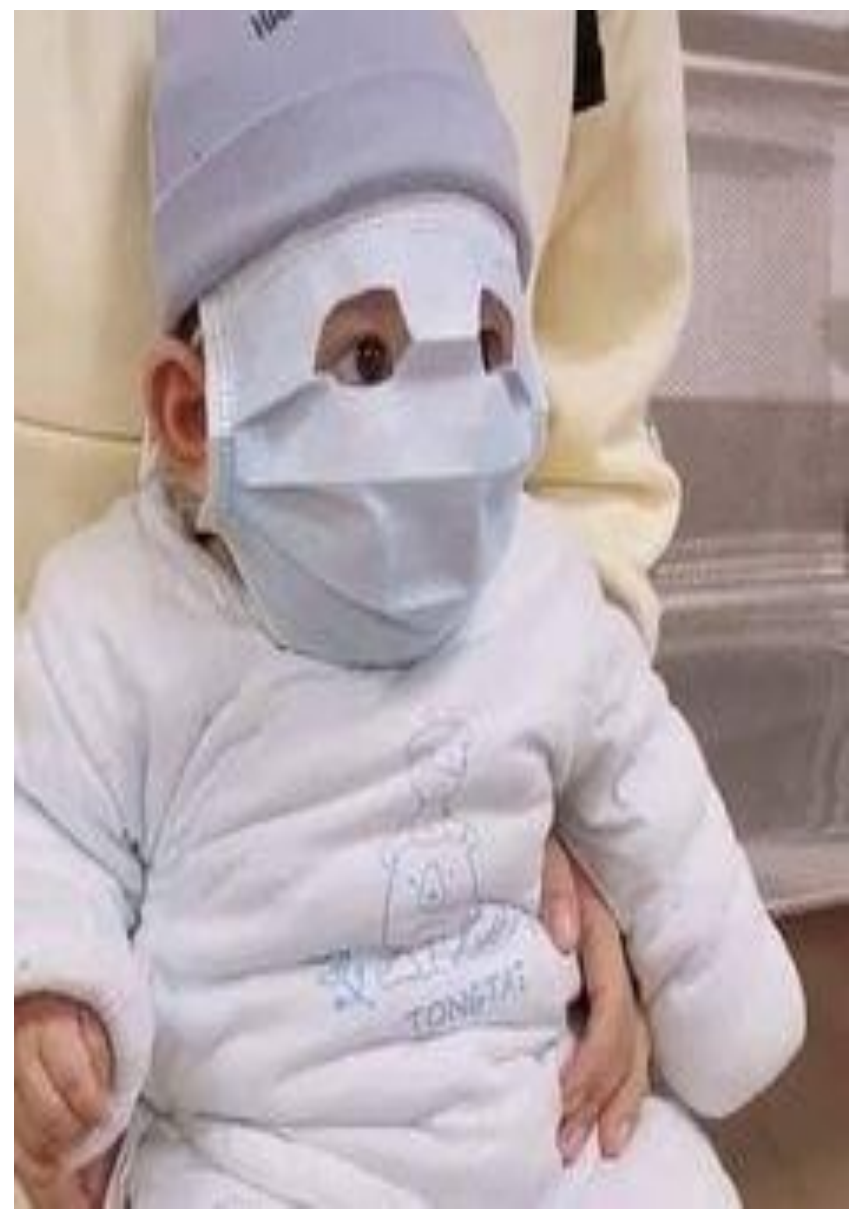

Figura 3. Foto engraçada

Fonte: https://cutt.ly/wdQx2hb

Fonte: https://cutt.ly/cdQHI74

Pesquisando outros tipos de memes para ser usados como materiais didáticos e pedagógicos nas aulas, nós como educadoras, pensando na educação infantil, encontramos uma dificuldade muito grande de encontrar imagens que não tivessem textos escritos. Como visto nas figuras 2 e 3 . Quando encontramos, pensamos que elas poderiam servir como prática pedagógica porque elas não têm texto e contextualizam o uso das máscaras. A figura 2 é uma figura clássica, porém junto com a figura 3 foram (re) imaginadas nesse contexto da proteção com o uso de máscaras contra o covid-19.

De acordo com Santos, Colacique e Carvalho (2016), os memes criados na internet podem ser entendidos como aspectos da realidade imagética e trazem com humor, elementos para a imaginação que recria e interpreta a realidade por eles representada. $\mathrm{O}$ seu jeito bem 
humorado e descontraído pode proporcionar usos nos cotidianos escolares a 'verouvirsentirpensar' a respeito dessa pandemia de forma mais leve e eficaz. Vemos a todo o momento novas imagens nas redes sociais carregadas de valores que podem ser de suma importância para disseminar as informações, e em especial, as de produção destinada para a infância, como por exemplo, o primeiro banho do cascão para se proteger da covid e outras doenças. É importante salientar que é necessário ter a mediação dos adultos, familiares ou professores, no contato dos memes com as crianças das mais variadas idades.

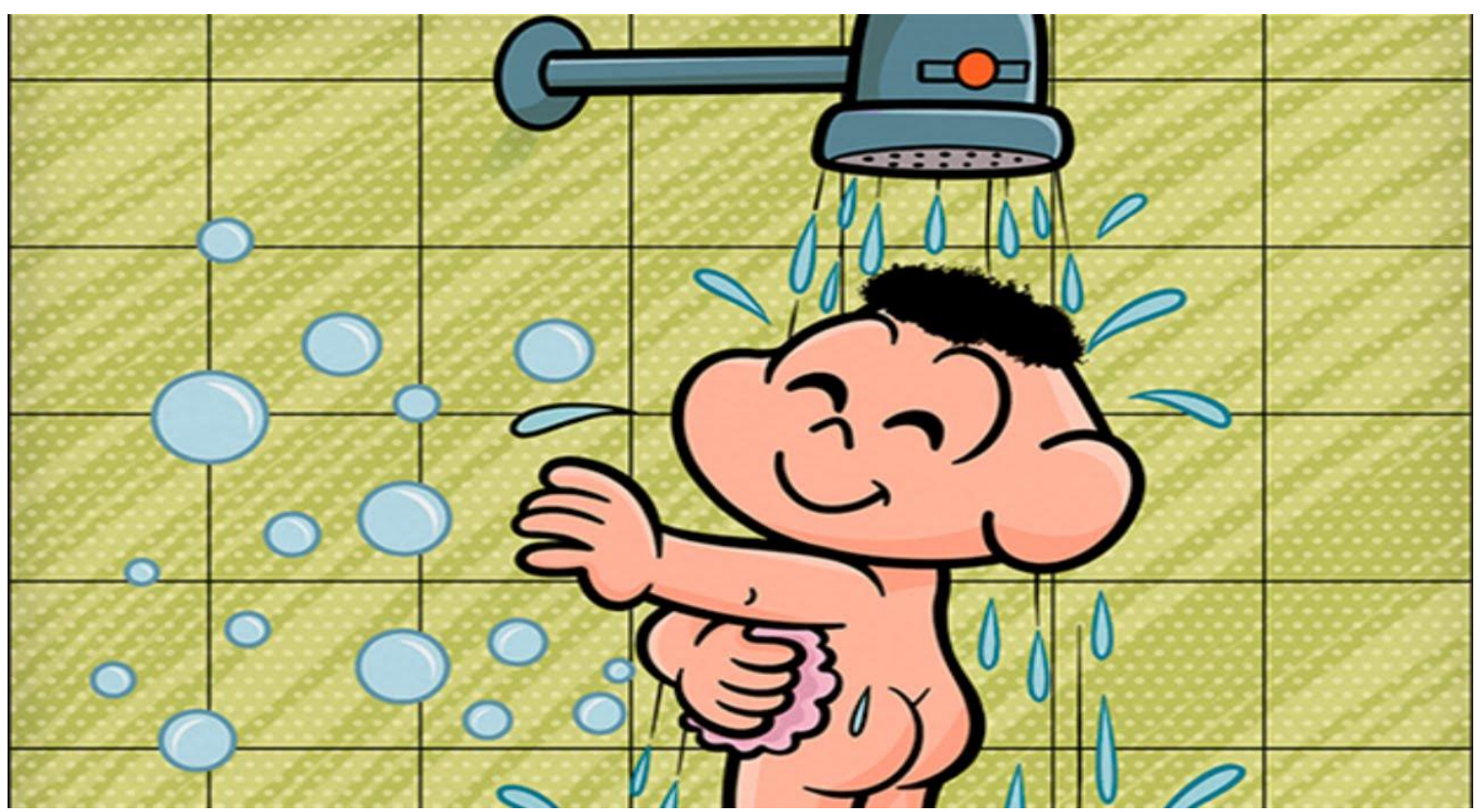

Figura 4. O primeiro banho do cascão

Fonte: https://url.gratis/DNjW4

Essas imagens são intercessores para podermos 'aprenderensinar' a nos prevenir e educar nossas crianças de forma lúdica, divertida e agradável. Assim sendo, essa genial ideia do escritor Mauricio de Sousa de fazer um personagem, como o cascão, tão avesso à água, tomar um banho para se proteger do vírus foi uma forma divertida de 'ensinoaprendizagem' nos 'dentrofora' das escolas. 


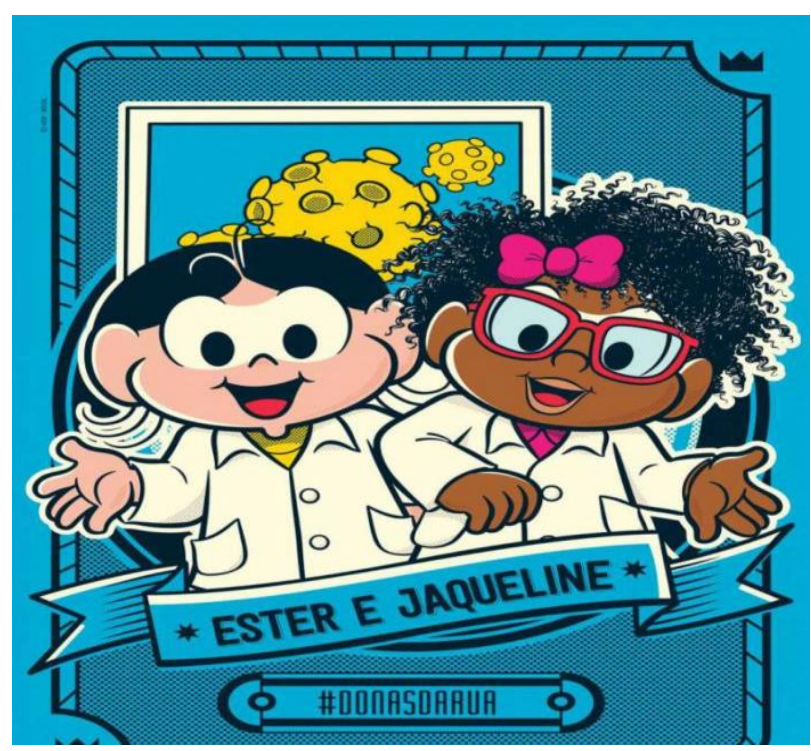

Figura 5. Homenagem de Maurício de Souza às duas cientistas brasileiras

Fonte: https://url.gratis/HdebM

O cartunista Mauricio de Souza fez uma excelente homenagem às duas cientistas brasileiras que tiveram papel fundamental no sequenciamento do genoma do novo coronavírus no Brasil. Ester Sabino e Jaqueline Goes de Jesus são duas jovens cientistas, e para nós é de estrema importância conhecer mulheres que fazem carreira científica. Essa é uma das formas de mostrar o "empoderamento feminino", palavra que tem sido frequentemente utilizada no âmbito dos mais diversos movimentos que lutam por igualdade social. Desta forma fica evidente que as mulheres podem ocupar seu lugar em todos os campos do saber.

\section{AS REDES COTIDIANAS E MIDIÁTICAS E AS DIVERGÊNCIAS QUE SE ENTRELAÇAM}

Em tempos de Cibercultura, vemos que uma ebulição tecnológica se dá através de artefatos portáteis e de fácil locomoção como smartphones e tablets. Muitas pessoas internadas, infectadas com o coronavírus, e que não podem receber visitas se comunicam através desses artefatos com aplicativos de mensagens ou até mesmo por chamadas de vídeo.

Se esses artefatos são usados dessa maneira tão intensa fora da escola, como podemos esperar que nela não aconteça o mesmo?

Caderno, livro, lápis, lápis de cor, caneta, borracha, apontador. Quadro negro, giz, mimeógrafo, compasso, régua, autofalante, apagador. Rádio, televisão, videocassete, DVD, retroprojetor. Máquina fotográfica, filmadora, pen drive, $\mathrm{CD}$, 
celular, quadro digital, computador. As intermináveis "listas de materiais escolares" exigidas aos alunos no início de cada ano letivo não param de crescer, incluindo novos e, há bem pouco tempo, impensados itens. Do mesmo modo, são incessantes as pressões de todos os lados (alunos, professores, gestores educacionais, pais, empresários, ativistas sociais, autoridades, especialistas e mídias) para que as escolas se "modernizem", se midiatizem, se informatizem, sob pena de se tornarem defasadas e desinteressantes em relação às mudanças no mercado de trabalho e à sedução provocada pela indústria de entretenimento, comprometendo, cada vez mais, a tão almejada e controvertida "qualidade do ensino". Por outro lado ainda, artefatos técnicos e tecnológicos diversos (nem sempre considerados apropriados ao contexto escolar) entram nas escolas pelas mãos e/ou através das experiências de alunos e professores (ALVES, SOARES, SANTOS, LIBANEO, 2012, p. 308, 309).

Além do tom leve e humorado dos memes, a internet tem sido cenário de inúmeras divergências de ideias acerca da pandemia. Uma grande parte da população já possui familiaridade com as redes sociais e usam a mesma para defenderem uma ideia. Sendo um momento de pânico e turbulência mundial essas ideias também podem divergir em muitos ambientes sociais como, por exemplo, na igreja, nas reuniões em família, em círculo de amigos, entre outros, mas, como o acesso e o circular a esses passos está restrito, tais conflitos se intensificam nas redes sociais.

No cotidiano cibernético, diversas notícias são compartilhadas através do Facebook, pelo Twitter, e por outras redes sociais. Geralmente essas notícias vêm acompanhadas com uma legenda que expõe a visão do internauta que compartilhou a notícia. Ou seja, muito além de compartilhar uma notícia o internauta defende seu ponto de vista, podendo discordar ou concordar do noticiário, baseado em algum tipo de conhecimento, seja ele cientifico ou popular.

\footnotetext{
Nunca acreditei em verdades únicas. Nem nas minhas, nem nas dos outros. Acredito que todas as escolas, todas as teorias podem ser úteis em algum lugar, num determinado momento. Mas descobri que é impossível viver sem uma apaixonada e absoluta identificação com um ponto de vista. No entanto, à medida que o tempo passa, e nós mudamos, e o mundo se modifica, os alvos variam e o ponto de vista se desloca. Num retrospecto de muitos anos de ensaios publicados e ideias proferidas em vários lugares, em tantas ocasiões diferentes, uma coisa me impressiona por sua consistência. Para que um ponto de vista seja útil, temos de assumi-lo totalmente e defendê-lo até a morte. Mas, ao mesmo tempo, uma voz interior nos sussurra: "Não o leve muito a sério. Mantenha-o firmemente, abandone-o sem constrangimento". (BROOK, 1995, p. 15)
}

Usando como base a citação acima, acreditamos que o maior desafio entre os 'praticantespensantes' que participam dessas divergências é a capacidade de mergulhar na ideia do outro e, em grande parte das ocasiões, isso se torna desafiador. Por que esse ato é considerado desafiador? Porque algumas ideias e pontos de vista do outro são capazes de 
ferir o que consideramos como coerente. Alguns 'praticantespensantes' consideram que questionar suas próprias filosofias e ideais pode se tornar contraditório, mas é preciso a abertura de reconhecer que não há verdades absolutas, mas sim redes com diferentes saberes. A partir disto vamos ao encontro da análise de redes educativas e cotidianos

São muitos os cotidianos de que fazemos partes. Plurais e complexos, os cotidianos não se resumem a única explicação, rompem com a dicotomia entre micro e microanálise e exigem de nós, um constante repensar das nossas práticas como pesquisadores. (ALVES, ANDRADE, CALDAS, 2019, p. 20)

Desta forma, dialogando com as autoras acima, podemos afirmar que não podemos enxergar os cotidianos nos quais temos uma maior familiaridade como únicos, quando na verdade todos os cotidianos, sem exceção, são plurais e contêm inúmeras explicações sobre um mesmo assunto. Partindo dessa lógica de estudo, se torna possível reconhecer a visão do outro acerca de alguma temática. Nesses debates virtuais podemos nos questionar sobre algumas questões que nos permitem até mesmo encontrar uma possível resposta para o porquê de determinado individuo defende uma ideia. Podemos questionar quais são os cotidianos e redes em que o mesmo convive e quais as influências que isso pode gerar em suas posições. E importante salientar que procurar compreender a ideia de um outro alguém não nos permite acolher discursos preconceituosos e desumanos, mas apenas nos questionar o fundamento de determinadas posições. Sendo assim:

\footnotetext{
O combate aos modos de pensar hegemônicos, indo de criações humanas em momentos anteriores, não se dá por dizer por dizermos como eles são maus ou insuficientes, não o foram no momento de seu surgimento e, ao contrário, foram revolucionários, pelo menos aqueles com que conversamos. (ALVES, ANDRADE, CALDAS, 2019, p. 20)
}

Isso nos trouxe à memória as inúmeras conversas e trocas que acontecem nas redes e de como é comum nos depararmos com algumas posições que são capazes de nos trazer os seguintes questionamentos: como esta ideia ainda pode ter credibilidade? Como os indivíduos ainda podem pensar dessa forma? A melhor explicação, se é que podemos chamar de explicação, é o desafio de analisarmos que determinadas posições já foram vistas como válidas em outro contexto social e político. Um exemplo do qual podemos fazer uso, neste momento de pandemia mundial, é o fato de alguns internautas se colocam contrários às medidas rígidas de isolamento, alegando que podem prejudicar a economia do país. Importante salientar que muitos fazem uso dessas notícias de forma tendenciosa mesmo tendo conhecimento de que se trata de uma notícia antiga que não deve mais servir como base, e outros fazem uso da mesma por ingenuidade ou carência de discernimento político e social, pois acreditam que como essa medida de não isolamento já foi válida em certo momento, pode ser considerada válida atualmente. Sendo assim, é importante sempre nos 
atentarmos ao histórico de defesa de uma ideia, porém repetimos o que já foi dito anteriormente, devemos atentar para a veracidade das notícias, sem tolerar discursos que ferem a dignidade humana.

\title{
AS DESIGUALDADES SOCIAIS EXPRESSAS NOS USOS DOS ARTEFATOS TECNOLÓGICOS
}

Como foi reforçado ao longo do artigo, o uso das tecnologias nos 'espaçostempos' escolares, se torna cada vez mais essencial, pois a tecnologia está cada vez mais presente, não apenas nos cotidianos escolares, mas em outros espaços sociais independente da nossa aceitação ou resistência a essas mudanças.

\begin{abstract}
A integração ao mundo tecnológico, midiático e informacional impõe-se como uma exigência quase universal, embora venha se realizando de forma desigual, e até mesmo marginal, conforme as diferenças sociais, econômicas, políticas e culturais entre as regiões do planeta e do pais, entre os grupos sociais e entre os indivíduo (ALVES, SOARES, SANTOS, LIBANEO, 2012: 309)
\end{abstract}

A citação acima reafirma o que vem sido trabalhado neste artigo sobre a valorização dos meios tecnológicos, pois os mesmos vêm se tornado cada vez mais úteis em nossos cotidianos. Porém, apesar de evidenciar a importância da integração ao mundo tecnológico as autoras não se poupam em fazer uma crítica à desigualdade que existe em nossa sociedade. Sabemos que o nosso país é marcado por uma desigualdade social que atinge os cidadãos de diversas maneiras. Sendo assim, apesar do uso dos meios tecnológicos serem quase uma exigência, nem todos os indivíduos têm acesso aos mesmos de forma igualitária e justa.

Uma notícia publicada pelo site NIC.br, em junho do ano de 2019, aponta que uma pesquisa realizada em 2017, pelo Instituto de Pesquisa Econômica Aplicada (Ipea) traz um estudo sobre o acesso desigual da Internet no Brasil. O mesmo foi realizado através dos dados de uma pesquisa TIC Domicílio 2017, produzida pelo Centro Regional de Estudos para o Desenvolvimento da Sociedade da Informação (Cetic.br). O resultado desse estudo aponta que as classes mais privilegiadas economicamente possuem um maior acesso á Internet: os dados mostravam que $90 \%$ dos cidadãos de classe A e B tem acesso à internet, já o percentual das classes $\mathrm{C}$ e D apontavam números inferiores a $42 \%$. O mesmo estudo também apontou que mais de $70 \%$ dos moradores da cidade possuem acesso à internet, porém nas áreas rurais as taxas são demostram que apenas $44 \%$ da população possui acesso à internet, uma porcentagem baixa comparada aos moradores da cidade. Ou seja, a desigualdade tecnológica tem como um dos fatores as distintas oportunidades de cada classe 
social. Sendo assim, quanto mais privilegiado o indivíduo for economicamente mais oportunidades o mesmo tem para acessar as tecnologias.

Ao longo do estudo fomos reconhecendo e percebendo a cada instante de nossas conversas e trocas, que não seria plausível escolher pela não problematização das desigualdades sociais, apesar da mesma se manifestar frequentemente em nossos 'espaçostempos', muitos ainda repetem uma falácia de que o acesso dos indivíduos a diversos direitos básicos como, por exemplo, saúde, educação, lazer são os mesmos e que os caminhos percorridos para que se possa usufruir desses direitos iguais depende do esforço individual, da meritocracia. Mas não precisamos ir muito além e nos aprofundarmos em pesquisas para percebemos que existe uma visão pouco problematizadora dessa questão. Dessa forma, o uso das tecnologias também não ocorre de maneira equilibrada, que alcance a todos, independente de classe social, poder econômico e localização geográfica. É de extrema importância frisar essa questão em um momento tão caótico em que se encontra o mundo, no qual a tecnologia tem se tornado cada vez mais presente e útil, principalmente para o ambiente educacional. Concluímos que muitos professores estão se sentindo acuados por esse momento, seja por não possuírem uma internet de qualidade satisfatória para a produção de vídeos aulas e para interações, seja pela questão de moradia que também dificulta o acesso à internet e talvez até mesmo pela ausência de um computador ou celular mais atual. A mesma carência é enfrentada pelos alunos de regiões ditas periféricas e, que o acesso é limitado e, às vezes, inexistente à internet. Desta forma, torna-se cada vez mais pertinente observar os 'espaçostempos' que frequentamos e, principalmente, aqueles que passam despercebidos ao nosso campo de visão, pois não podemos ser incoerentes enquanto 'praticantespensantes' que observam apenas o seu cotidiano, ignorando outras realidades.

Nas trocas de experiências que tecemos durante o trabalho, percebemos também nossas diferenças locais em relação ao uso de uma internet de qualidade. Analisamos que o local de moradia de uma era mais favorável para uma internet que fosse capaz de permitir gravação de inúmeras vídeo-aulas para as crianças, enquanto a outra sofria com as consequências de uma internet de má qualidade, devido ao seu local de moradia. Ou seja, a dificuldade não se encontra apenas em se familiarizar com as câmeras, mas também em conseguir viabilizar o primeiro passo que é ter o acesso a uma internet de qualidade. Porém, independente desses impedimentos, seguimos resistindo e criando de acordo com as novas possibilidades que nos surgem.

\section{CONSIDERAÇÕES FINAIS}


Finalizamos o presente estudo com uma carga de responsabilidade e orgulho. Responsabilidade por saber que, como educadoras 'praticantespensantes' temos conosco o compromisso social de perceber nossos 'espaçostempos', além do que vivenciamos, para assim tecermos questionamentos e criações a partir disso, como foi o fato de perceber, ao longo do trabalho, que muitas educadoras e alunos se encontram, de certo modo, excluídos dos processos tecnológicos.

Orgulho por observarmos como a educação se encontra presente e é necessária em cada contexto político e social de nossa história. Sempre lemos em noticiários que existem os profissionais que estão na linha de frente dessa pandemia, como enfermeiros, médicos entre outros. Sem dúvida isso e uma verdade incontestável, mas acreditamos que a Educação também se coloca como retaguarda a essa pandemia, mesmo que as escolas estejam fechadas temporariamente. O trabalho do professor não parou, pelo contrário, esse é o momento de criação através contatos e atividades como aulas online para seus alunos, é o momento de se inspirar em diversos memes educativos que estão indo além de criar humor na internet, mas também possuem uma carga educativa como, por exemplo: os memes do cascão, entre outros. E também é o contexto propício para analisarmos os debates que vem acontecendo na internet de uma maneira crítica percebendo que cada 'praticantepensante' defende sua ideia baseado em suas redes cotidianas. Trilhando esse caminho nos consideramos cada vez mais aptas às criações e resistências educativas, independente dos 'espaçostempos' escolares, ou seja, reafirmando que a resistência e a criação de um professor ultrapassam os muros físicos das instituições de ensino.

\section{Referências}

ALVES, Nilda. Decifrando o pergaminho - os cotidianos das escolas nas lógicas das redes cotidianas. In: OLIVEIRA, Inês Barbosa de; ALVES, Nilda (orgs). Pesquisas nos/dos/com os cotidianos escolas. Petrópolis: DP et Alii, 2008.

ALVES, Nilda. A compreensão de políticas nas pesquisas com os cotidianos: para além dos processos de regulação. Educ. Soc., Campinas, v. 31, n. 113, p. 1195-1212. 2010. Disponível em: \&lt;http://www.cedes.unicamp.br\&gt;. Acesso em: março., 2020. 
ALVES, Nilda et alii. Os movimentos necessários às pesquisas com os cotidianos - após muitas 'conversas' acerca deles. In: Inês Barbosa de Oliveira, et al (orgs). Estudos do cotidiano, currículo e formação docente; questões metodológicas, políticas e epistemológicas. Curitiba: CVR, 2019, p. 18-45.

ALVES, Nilda Praticantespensante de cotidianos/organização e introdução Alexandra Garcia, Inês Barbosa de Oliveira: Textos selecionados de Nilda Alves- 1.ed_ Belo Horizonte: Autêntica

Editora, 2015.

ALVES, Nilda et alii. Os movimentos necessários às pesquisas com os cotidianos - após muitas 'conversas' acerca deles. In: Inês Barbosa de Oliveira, et al (orgs). Estudos do cotidiano, currículo e formação docente; questões metodológicas, políticas e epistemológicas. Curitiba: CVR, 2019, p. 199-211.

ALVES, Nilda; FERRAÇO, Carlos Eduardo. As pesquisas com os cotidianos das escolas: pistas para se pensar a potência das imagensnarrativas na invenção dos currículos e da formação. ESPAÇO DO CURRÍCULO, v.8, n.3, p. 306 - 316, setembro a dezembro de 2015.

BRASIL. Secretaria de Educação Fundamental. Parâmetros curriculares nacionais: apresentação dos temas transversais, ética / Secretaria de Educação Fundamental. - Brasília: MEC/SEF, 1997.

FERNANDES, A. H., DINIZ, L.A., BARROS, R. S. Tecnologias digitais nas escolas: outras possibilidades para o conhecimento. Org. AMARO, Ivan, SOARES, M. C. S. 1 ed. De Petrus et Alii. Rio de Janeiro. 2016

PAIVA, Lauriana Gonçalves de. Do giz colorido ao data show: uma conex@odesconect@d@ da realidade escolar. Dissertação (Mestrado) - Universidade Federal Fluminense, Faculdade de Educação, 2005

SANTOS, Edmea Oliveira dos; CARVALHO, Felipe da Silva Ponte de; SANTOS, Rosemary dos. Sessão Temática: Redes Educativas e mediações digitais: tensões e 
insurgências de formação. REVISTA TEIAS v. 21 n 60 jan/mar.2020.Disponível em: https://www.e-publicacoes.uerj.br/index.php/revistateias/issue/view/2288/showToc

SANTOS, Edmea.; COLACIQUE, Rachel.; CARVALHO, Felipe da Silva Ponte. A autoria visual na internet: o que dizem os memes?. Quaestio - Revista de Estudos em Educação, v. 18, n. 1, p. p. 135-157, 13 jul. 2016. Disponível em: http://periodicos.uniso.br/ojs/index.php/quaestio/article/view/2570/2168

SOARES, C. SANTOS, E. Artefatos tecnoculturais nos processos pedagógicos: usos e implicações para os currículos. In: ALVES, Nilda. Libâneo, José Carlos. Temas de Pedagogia: diálogos entre didática e currículo. São Paulo: Editora Cortez, 2012. (p. 308$330)$.

https://g1.globo.com/ciencia-e-saude/noticia/2020/01/23/coronavirus-como-e-wuhan-acidade-chinesa-onde-surgiu-a-epidemia-de-coronavirus-e-que-foi-isolada.ghtml (acesso em: $24 / 03 / 2020$.

http://periodicos.uniso.br/ojs/index.php/quaestio/article/view/2570/2168 (acesso em 04/04/2020.)

https://brasil.elpais.com/internacional/2020-02-28/italia-muda-estrategia-contra-ocoronavirus-para-combater-o-alarmismo-e-proteger-a-economia.html (acesso em: 02/04/2020).

Este é um artigo de acesso aberto distribuído sob os termos da Licença Creative Commons Atribuição Não Comercial-Compartilha Igual (CC BYNC- 4.0), que permite uso, distribuição e reprodução para fins não comerciais, com a citação dos autores e da fonte original e sob a mesma licença. 